\title{
An Exploration of Quality in Online Course Teaching and Practice
}

\author{
Mingfa Yao ${ }^{1}$ \\ ${ }^{1}$ Zhejiang International Studies University, Hangzhou, China \\ Correspondence: Mingfa Yao, Zhejiang International Studies University, Hangzhou, China.
}

Received: September 29, 2021

doi:10.20849/aes.v7i1.929
Accepted: October 21, $2021 \quad$ Online Published: February 10, 2022

URL: https://doi.org/10.20849/aes.v7i1.929

\begin{abstract}
This paper takes into consideration of the problems discovered in the quality of online course teaching in the University and cooperates with related departments to conduct a survey on quality of online course teaching and practice, with the purpose of detecting how students evaluate their online course teaching and learning at present, analyzing the factors that influence the online teaching quality, and proposing some strategies to facilitate and improve online evaluation of teaching and enhance education and teaching quality in the University.
\end{abstract}

Keywords: teaching quality, exploration, online course, teaching and practice

\section{Introduction}

Teaching quality is the lifeline of curriculum and teaching as well as the important support of specialty development. Evaluation of teaching quality is an important part of teaching management in universities. To evaluate the teaching quality scientifically, comprehensively, objectively and justly can reflect the teachers' moral level and teaching literacy as well as students' ability development. Exploring the evaluation of teaching quality is a very important work both theoretically and practically.

With the outbreak of COVID-19, online course teaching has become the norm in colleges and universities. In recent years, China has implemented the "Double Ten Thousand Plan" for first-class undergraduate courses, clearly proposing to build a batch of high-quality online open courses, and identifying 10,000 national or provincial high-quality online open courses. At the same time, colleges and universities are encouraged to develop standards for teaching quality. Teaching quality evaluation has become an important content of online course evaluation, as well as an important indicator of course construction quality, aiming at promoting the improvement of online course teaching quality.

But from existing literature and the schools, we found that a large-scale online university course teaching is not fully well-prepared. At the beginning of the online teaching, there is no unified teaching platform, but various teaching platforms are freely chosen by the teachers, more than ten kinds of online teaching platform. Their network teaching effect varies and the online teaching quality standard is not perfect. University-based online teaching quality assurance system needs to be constructed and its effectiveness needs to be improved. The identification of the teaching quality of online courses at the University level is a comprehensive assessment of whether the teaching quality of online courses meets the actual needs of the students under the premise of "guaranteeing the teaching quality", focusing on the identification and introduction of courses that meet the actual needs of colleges and universities.

What is the teaching quality and effect of implementing large-scale online teaching courses? How to build the quality assurance system of online course teaching? Based on the online course teaching quality evaluation standards, this study is to explore the objects of online teaching by carrying on the survey from the five aspects on the quality of online teaching, including course and the teaching goal, teaching content and resources, the teaching activity and the implementation of curriculum and teaching evaluation as well as the effect of early operation and 20 concrete contents. Some relevant teaching management, experts and students are interviewed about the teaching quality, aiming to discuss and analyze the content and effect of the evaluation of the teaching quality of online courses.

\section{Literature Review}

\subsection{Analysis of Online Teaching Quality Evaluation}

Due to the influence of COVID-19, online course teaching has been widely used in various colleges and 
universities at all levels. They actively carry out online teaching and learning and other online teaching activities, and strive to ensure that online learning and offline classroom teaching achieve the same teaching effect. Since February 2020, the Ministry of Education in China has issued some documents for the Organization and Management of Online Teaching in Institutions of Higher Learning during the Prevention and Control of the Epidemic in response to the online course teaching in crisis situations. In order to ensure the quality of online teaching, colleges and universities have tried to carry out teaching quality evaluation. Some colleges and universities promote the steady improvement of the quality of online teaching by establishing online teaching evaluation mode of multi-participation, multi- dimensional evaluation, timely feedback, information closed-loop, supervision and guidance, etc. Some colleges and universities carry out online course research, propose to adhere to the teaching quality evaluation system, and use the questionnaire and platform feedback to timely carry out teaching quality evaluation and research activities for teaching administrators, supervisors, peers, teachers and students to monitor the teaching quality. In addition, colleges and universities have established a checklist system to conduct whole-process supervision, track and verify online teaching and learning, and ensure that online and offline courses are "substantially equivalent".

In the spring semester of 2020, Zhejiang International Studies University also launched a comprehensive online teaching program in accordance with the nationwide trend of launching online courses. During the epidemic prevention and control period, there were 12 teaching units and 1,925 undergraduate courses conducting online teaching, with an overall course opening rate of $95.61 \%$. 445 teachers participated in the online teaching, accounting for $92.3 \%$ of all the teachers in the University. More than 20,000 students participated in the online courses every week. After the first three weeks of teaching, most of the courses were taught online at the normal teaching pace. In view of the large-scale online teaching, the university has formulated the online course teaching quality evaluation work plan, which adopts four ways to evaluate the online course teaching quality, namely, the management personnel listening to the class, watching the class, the two levels (university and schools) of supervision listening to the class, peer teachers listening to the class and the student satisfaction evaluation. During the online course teaching, school-level teaching supervision experts have attended and evaluated 216 times, and the excellent rate of online course evaluation is $92 \%$. University-level teaching supervision experts have attended and evaluated 312 lectures, and the excellent and good rate of online course evaluation is $93 \%$. The teaching management staff of the schools and the teaching and research section attended and evaluated 568 lectures, and the excellent and good rate of online course evaluation was $95.6 \%$. Peer teachers have attended and evaluated 1256 lectures, and 97\% of the online course evaluation rates are excellent. Students' evaluation of teaching is mainly conducted through the form of online questionnaires. A total of 8,096 questionnaires were distributed, and $91.5 \%$ of the students were very satisfied or satisfied with the online courses.

\subsection{Problems in Online Teaching Quality Evaluation}

Online teaching quality evaluation system is established based on the traditional classroom teaching quality evaluation system. The traditional system usually introduces diversified evaluation subjects, adopts quantitative and qualitative evaluation indexes and multi-channel evaluation methods, and has established a set of relatively complete evaluation system. Online teaching and traditional classroom teaching have certain differences in the carrier and form. The traditional classroom teaching quality evaluation can provide the experience basis for the online teaching quality evaluation, but it cannot copy the traditional quality evaluation model. According to the existing literature, various universities have made a variety of attempts in online teaching quality evaluation. However, due to the short time of online teaching, it is still difficult to establish a complete set of teaching quality evaluation system, and further practice is needed.

\subsubsection{Lack of Scientific Teaching Idea}

In order to promote the development of teaching activities, online teaching has become the first choice of many universities. The goal of each university is to achieve the "substantial equivalence" between online teaching and offline teaching. Therefore, the online teaching quality evaluation is similar to the offline teaching quality evaluation in form and content. But online and offline teaching is more than just a change in class form.

Through the analysis of the development process of online teaching, it can be seen that online teaching is not a substitute for the traditional offline teaching, but to promote the development of teaching by giving play to the role of the Internet in education and teaching. It is fundamentally different from the traditional offline teaching in many aspects. Therefore, it is worth pondering whether we should evaluate the effect of online teaching with the traditional concept of offline teaching. And the current online teaching is often directly transferred from the traditional teaching in the quality and objectives, which obviously does not have enough been targeted. Focusing 
on the two different teaching methods of online teaching and traditional classroom teaching, we should evaluate the teaching quality evaluation differently. We should pay attention to the essential difference between online teaching and traditional classroom teaching, and online teaching should not copy the quality goal of traditional classroom teaching in general.

\subsubsection{The Weak Applicability of Evaluation Index}

Online teaching quality evaluation index system is established on the basis of the traditional classroom teaching quality evaluation, so its index design is also based on the traditional classroom teaching quality evaluation index. Through the comparative study of several online teaching quality evaluation indicators of universities, it can be found that there are several problems in the design of online teaching quality evaluation indicators: First, the online teaching quality evaluation index is a simple conversion of the traditional classroom teaching evaluation index. The evaluation index mainly covers teaching preparation, teaching process, teaching effect, teaching and educating people, etc. The index design does not highlight the characteristics of online teaching, and the pertinence is not strong. Secondly, online teaching quality evaluation index design does not suit the actual situation of online teaching, for example, some universities evaluate the efficacy of the online teaching by applying design management, supervision, and other third-party evaluation subject to the effect of classroom teaching evaluation index with the knowledge of the students in the classroom to grasp the situation, as well as the students' utilizing learning resource uploaded by the teachers. Different from the traditional classroom teaching quality evaluation, it is difficult for teaching administrators, teaching supervisors or peer teachers to intuitively see students' reactions to the class teaching and learning when they attend the online teaching class. As a result, such indicators lack operability and are difficult to give a true feedback on the quality of online teaching. Third, the design of online teaching quality evaluation indicators did not take into account the differences of the evaluation subjects. The reason why the teaching quality evaluation should introduce many subjects such as students and teaching supervisors is to guarantee the integrity and objectivity of the teaching quality evaluation. At present, it is not significant in the differences of the dimensionality of evaluation among various evaluation subjects, and the emphasis is not strong. Furthermore, the advantages of each evaluation subject in teaching quality evaluation are not highlighted.

\subsubsection{The Insufficient Motivation of the Evaluation Subjects}

The final implementation of online teaching quality evaluation depends on the effective participation of various evaluation subjects. In order to guarantee the quality of online teaching, most universities have established institutions to supervise and manage the quality of online teaching. Most of the evaluation subjects of online teaching quality evaluation are the subjects of traditional classroom teaching quality evaluation. They establish an evaluation system involving multiple subjects such as school leaders, teaching supervisors, teaching administrators, peer teachers and students. But in practice, not every subject can fully participate in the online teaching quality for a clear and objective evaluation. Because online teaching is still the first large-scale application, it is difficult for some evaluation subjects to enter different online platforms to see teachers' teaching conditions. Moreover, some of the evaluation subjects have no experience in online teaching, so it is hard to effectively evaluate the difficulties in online teaching. To let every subject participate in online teaching evaluation becomes a "prescribed action", and it is not significant to really improve the teaching.

\subsubsection{Insufficient Application of the Evaluation Results}

Teaching quality evaluation needs to pay attention not only to the teaching process of teachers, but also to the learning situation of students, and to ensure the internal consistency between high quality teaching and learning, so as to continuously improve the teaching quality. However, the current online teaching quality evaluation is more for the purpose of obtaining the evaluation results, neglecting the application of the evaluation results and not paying enough attention to the improvement of teaching quality. Due to the lack of in-depth analysis of the results of online teaching quality evaluation and the failure to fully explore the difficulties existing in online teaching, online teaching quality evaluation has not been able to effectively improve online teaching.

\subsection{Online Teaching Quality Evaluation Research}

Teaching quality is a key determinant of students' learning outcomes during their school years (Darling-Hammond, 2007; Kyriakides, Christoforou \& Charalambous, 2013). However, in the context of higher education, especially in online learning, the evidence to support a similar link is not enough. In addition, in an online learning setting, technology can be taken as a medium of teaching and learning experience. Those methods that determine the quality of instruction in an offline face-to-face classroom setting are not necessarily appropriate in an online course setting, particularly in the impact of technology on the student's learning experience (Ginns \& Ellis, 2007). The definition and assessment of instructional quality in an online learning 
environment has been a central focus of recent research and discussion on online education (Garrison, 2011). Many people believe that online learning environments are fundamentally different from traditional classrooms. Early research on the principles of online course teaching focused on teacher-student interaction, encouraging collaboration and active learning, giving timely feedback, and setting clear deadlines, all with clear guidance (Graham, Cagiltay, Lim, Craner, \& Duffy, 2001). Although the guidelines of many early studies acknowledge the importance of pedagogy, they tend to focus more on functional support for specific online environments, such as accessibility, communication, interface reliability and bandwidth requirements (Herrington, Herrington, Oliver, Stoney \& Willis, 2001). Recent research has focused on general pedagogical principles that apply to any online delivery system (Kidney, Cummings, \& Boehm, 2014; Margaryan, Bianco and Littlejohn, 2015). Some researchers advocate that more research should be conducted in an online environment to "examine the learning theories and teaching models inherent in curriculum design by informing learners' outcomes, learners' characteristics, course environment, and institutional factors related to the system variables of delivery".(Tallent-Runnels et al., 2006, p.93). Some believe that the development of these models can benefit from the rich and well-developed classroom teaching research available (Haythornthwaite \& Andrews, 2011). In comparison with face-to-face teaching, a major problem with early online learning studies is that the concept of "lesson" is completely different in a non-classroom teaching environment (De Wever, Schellens, Valcke, \& Van Keer, 2006). Courses in online and hybrid environments can be understood as "units of learning" through a variety of media, including forums, blogs, and email exchanges with individuals related to the academic aspects of the teaching. Therefore, what can be studied and analyzed is mainly the interaction that takes place through these media. In general, these interactions refer to student-student, student-teacher, or student-content interactions. Studies have found that the frequency of interaction is associated with the improvement of students' performance (Bernard et al., 2009; Tamin et al., 2011). Many different tools and measures can be used to analyze the content of online interactions, although concerns have been raised about the effectiveness and reliability of some of these tools (De Wever et al., 2006).

\section{Methodology}

\subsection{Participants}

The participants of this study are undergraduates of a university. In March 2021, a self-compiled questionnaire was used to carry out the "Online Course Teaching Quality Questionnaire". 475 questionnaires were randomly distributed to students of the 6 colleges in the university, and 475 were collected with a response rate of $100 \%$ and an effective rate of $100 \%$, including 365 for the grade 2019 and 110 for grade 2020. The basic composition of the respondents is shown in Table 1.

Table 1. Participants

\begin{tabular}{lccc}
\hline Variables & Types & Numbers & Percent \\
\hline Grades & 2019 & 365 & $76.8 \%$ \\
Colleges & 2020 & 110 & $23.2 \%$ \\
& $\begin{array}{c}\text { College of Eastern } \\
\text { Languages and } \\
\text { cultures }\end{array}$ & 54 & 11.36 \\
& $\begin{array}{c}\text { College of Western } \\
\text { Languages and } \\
\text { cultures }\end{array}$ & 53 & 11.16 \\
& $\begin{array}{c}\text { College of Chinese } \\
\text { and cultures } \\
\text { College of } \\
\text { Education }\end{array}$ & 45 & \\
& $\begin{array}{c}\text { College of Science } \\
\text { and Technology } \\
\text { College of Art } \\
\text { College English }\end{array}$ & 133 & 9.48 \\
Majors courses & 106 & 17.68 \\
courses & 436 & 28 \\
& & 39 & 22.32 \\
& & & 91.79 \\
\end{tabular}




\subsection{Research Design and Data Analysis}

The questionnaire is based on students' basic information, including grade, school, and online course teaching quality. Among them, the quality content survey mainly consists of multiple choices. The Likert 5 subscale of the subjective perception method is adopted to investigate the students' opinions to the statements of all aspects of online teaching quality, namely, 1-5 are respectively strongly disagree, disagree, not sure, agree, strongly agree. Online course teaching quality includes course and teaching objectives, course teaching content and resources, course teaching activities and implementation, course and teaching evaluation, as well as course early operation and effect. Data processing software SPSS 21.0 is used for data processing in this study. At the same time, relevant teaching management, experts and students were selected for the interview about the teaching quality.

\section{Results}

\subsection{Course and Teaching Objectives}

This part includes three aspects: whether the course design and implementation can fully reflect the course concept of "learner-centered" or not; whether the course is well connected with the leading courses and follow-up courses of the school or not; and whether the teaching objectives of the course are suitable for the requirements of professional training and the needs of learners. The following Table 2 is the result of these statements.

Table 2. Course and teaching objectives

\begin{tabular}{lllllllllll}
\hline \multirow{2}{*}{$\begin{array}{l}\text { Statement } \\
\text { No. }\end{array}$} & \multicolumn{2}{l}{ Strongly agree } & \multicolumn{2}{c}{ agree } & Not sure & \multicolumn{2}{c}{ Disagree } & \multicolumn{2}{c}{ Strongly disagree } \\
\cline { 2 - 12 } & Frequency & Percent & Frequency & Percent & Frequency & Percent & Frequency & Percent & Frequency & Percent \\
\hline 1 & 231 & 48.53 & 146 & 30.67 & 84 & 17.65 & 10 & 2.1 & 5 & 1.05 \\
\hline 2 & 227 & 47.69 & 142 & 29.83 & 80 & 16.81 & 18 & 3.78 & 9 & 1.89 \\
\hline 3 & 230 & 48.32 & 134 & 28.15 & 89 & 18.7 & 12 & 2.52 & 11 & 2.31 \\
\hline
\end{tabular}

For the first statement "The design and implementation of online courses reflect the idea of "learner-centered" in online teaching", 79.2 percent of the students agree or strongly agree the statement, 17.65 percent of the students are not sure of it, and only 3.15 percent of students disagree or strongly disagree. The result of the second statement of "Online courses can be connected with professional introductory courses and follow-up courses" tells us that 87.52 percent of the students agree or strongly agree the statement, 16.81 percent of the students are not sure of it, and 5.67 percent disagree or strongly disagree. For the third statement "The teaching objectives of online courses are appropriate to the requirements of professional training and the needs of learners." 76.47 percent of the students agree or strongly agree, and 4.83 percent of the students disagree or strongly disagree.

\subsection{Course Contents and Resources}

This part includes the course teaching experience and high teaching level, course teaching content system for online learning, mixed teaching and other teaching models, various course learning resources for the learning needs of different learners, navigation design for the rapid positioning of teaching content and learning resources, generative resources and update teaching content in time. The following Table 3 shows the result.

Table 3. Course contents and resources

\begin{tabular}{|c|c|c|c|c|c|c|c|c|c|c|}
\hline \multirow{2}{*}{$\begin{array}{l}\text { Statement } \\
\text { No. }\end{array}$} & \multicolumn{2}{|c|}{ Strongly agree } & \multicolumn{2}{|c|}{ agree } & \multicolumn{2}{|l|}{ Not sure } & \multicolumn{2}{|l|}{ Disagree } & \multicolumn{2}{|c|}{ Strongly disagree } \\
\hline & Frequency & Percent & Frequency & Percent & Frequency & Percent & Frequency & Percent & Frequency & Percent \\
\hline 4 & 265 & 55.67 & 145 & 30.46 & 59 & 12.39 & 5 & 1.05 & 2 & 0.42 \\
\hline 5 & 249 & 52.31 & 138 & 28.99 & 69 & 14.5 & 9 & 1.89 & 11 & 2.31 \\
\hline 6 & 243 & 51.05 & 131 & 27.52 & 87 & 18.28 & 7 & 1.47 & 8 & 1.68 \\
\hline 7 & 239 & 50.21 & 139 & 29.2 & 78 & 16.39 & 12 & 2.52 & 8 & 1.68 \\
\hline 8 & 233 & 48.95 & 141 & 29.62 & 80 & 16.81 & 12 & 2.52 & 10 & 2.1 \\
\hline
\end{tabular}


The fourth statement concerns the online course teachers' teaching experience and teaching level. The table 3 shows that 86.13 percent of the students agree or strongly agree that the teachers have rich experience and high teaching level. Less than 2 percent of the students disagree or strongly disagree with the opinion, about 12.39 percent of the students are not sure about the statement. This result shows that most of the teachers are qualified to the online teaching and have high teaching level.

Statement 5 elicits opinions from the students varying on whether online course teaching content system can be suitable for online learning, mixed teaching and other teaching models. Table 3 gives the results of the statement on the questionnaire. About 81.3 percent of students 'agrees' or 'strongly agrees' with the opinion on the question. This shows that most of the students have appreciated their teachers' qualification. Less than 5 percent (4.2) of the students disagree or strongly disagree with the statement, but 14.5percent of the students are not sure of their opinions.

For the statement 6 "Online courses are rich in learning resources and present various forms, which can meet the learning needs of different learners", Table 3 displays that 78.57 percent of the students agrees or strongly agrees with the statement, and only 3.15 percent of the students disagree and strongly disagree with the statement. We note that about one-fifth of the students are uncertain about the statement. Some of the objects say some of the teaching material cannot meet their learning needs.

Statement 7 says that whether online course navigation design can realize the rapid positioning of teaching content and learning resources. The result shows that 79.41 percent of the students agree or strongly agree with the statement, and 4.2 percent of the students disagree or strongly disagree with the opinion. But there are still 16.39 percent of the students are not sure of their opinion.

Table 3 also show the result of the statement 8 that online courses focus on the various states and performance of students, and can update the teaching content in time. 79.57 percent of the students support the statement, and 4.62 percent disagree or strongly disagree with the statement. 16.81 percent of the students are not sure of their opinion.

\subsection{Course Teaching Activities and Implementation}

This part includes five statements of whether the technology environment of online courses effectively supports online teaching activities and interactive teaching activity form; Whether the teaching methods of online courses support learners' strong sense of participation and online/offline interaction between teachers and students and students and whether the online courses provide personalized support services for academic, emotional, management, etc. This following Table 4 is the result of this part.

Table 4. Course teaching activities and implementation

\begin{tabular}{lllllllllll}
\hline \multirow{2}{*}{$\begin{array}{l}\text { Natement } \\
\text { No. }\end{array}$} & \multicolumn{2}{l}{ Strongly agree } & agree & \multicolumn{2}{c}{ Not sure } & \multicolumn{2}{c}{ Disagree } & \multicolumn{2}{c}{ Strongly disagree } \\
\cline { 2 - 11 } & Frequency & Percent & Frequency & Percent & Frequency & Percent & Frequency & Percent & Frequency & Percent \\
\hline 9 & 251 & 52.73 & 152 & 31.93 & 60 & 12.61 & 7 & 1.47 & 6 & 1.26 \\
\hline 10 & 234 & 49.16 & 134 & 28.15 & 88 & 18.49 & 11 & 2.31 & 9 & 1.89 \\
\hline 11 & 235 & 49.37 & 145 & 30.46 & 72 & 15.13 & 14 & 2.94 & 10 & 2.1 \\
\hline 12 & 244 & 51.26 & 135 & 28.36 & 77 & 16.18 & 11 & 2.31 & 9 & 1.89 \\
\hline 13 & 224 & 47.06 & 137 & 28.78 & 85 & 17.86 & 17 & 3.57 & 13 & 2.73 \\
\hline
\end{tabular}

Table 4 displays the result of the statement 9 "Online course technology environment can effectively support online teaching activities." 84.66 percent of the students support the opinion of the statement, and 2.73 percent of the students disagree or strongly disagree the statement. But 12.61 percent of the students are not sure of the statement.

Statement 10 says that whether the teaching activities of online courses are diversified and interactive. The table 4 shows the result that 77.31percent of the students agree and strongly agree with the statement, only 4.2 percent of the students disagree and strongly disagree with the statement. 18.49 percent of the students are not sure of the opinion.

We assume that online courses teaching will support students to participate in class. Table 4 confirms the assumption. Most of the students (79.83\%) in the sample 'agree' or 'strongly agree' with the point in the 
statement; only 5.04 percent of the students 'disagree' or strongly disagree with the statement and 15.13 percent of the subjects are uncertain. This is again in accordance with the idea that "teachers try their best to support students to participate the online learning.

Statement 12 is also about the interaction between teachers and students in their online and offline teaching and learning. Online courses can well support online and offline interaction between teachers and students. The result shows that 79.62 percent of the students agree or strongly agree with that supporting. Only 4.2 percent of the students disagree or strongly disagree with the statement.

For the statement 13 that online courses offer personalized support for academic, emotional, management, and more, Table 4 displays the result that 75.84 percent of the students agree or strongly agree with the statement, whereas 6.3 percent of the students disagree or strongly disagree with it, and about 17.86 percent of the students are not uncertain with the opinion.

\subsection{Course and Teaching Evaluation}

This part includes three statements of whether the online courses support exercise, homework, discussion and other process evaluation methods; whether online courses support final evaluation of different application modes online and offline; whether online courses support evaluation of content, platform, service and course management. Table 5 shows the result of these statements.

Table 5. Course and teaching evaluation

\begin{tabular}{|c|c|c|c|c|c|c|c|c|c|c|}
\hline \multirow{2}{*}{$\begin{array}{l}\text { Statement } \\
\text { No. }\end{array}$} & \multicolumn{2}{|c|}{ Strongly agree } & \multicolumn{2}{|c|}{ agree } & \multicolumn{2}{|l|}{ Not sure } & \multicolumn{2}{|l|}{ Disagree } & \multicolumn{2}{|c|}{ Strongly disagree } \\
\hline & Frequency & Percent & Frequency & Percent & Frequency & Percent & Frequency & Percent & Frequency & Percent \\
\hline 14 & 249 & 52.31 & 140 & 29.41 & 73 & 15.34 & 8 & 1.68 & 6 & 1.26 \\
\hline 15 & 240 & 50.42 & 146 & 30.67 & 73 & 15.35 & 10 & 2.1 & 7 & 1.47 \\
\hline 16 & 245 & 51.47 & 138 & 28.99 & 77 & 16.18 & 9 & 1.89 & 7 & 1.47 \\
\hline
\end{tabular}

Table 5 displays the result of three statements about the teaching and learning evaluation. In the statement 14 , the result displays that 81.72 percent of the students agree or strongly agree with the statement, only 3.14 percent of the students disagree or strongly disagree with it, and 15.34 percent are uncertain.

In response to statement 15 which says that whether the online course has support for the final evaluation of different teaching applications in both online and offline. It was evident that responses to the opinion tilted toward agreement, 81.09 percent of the sample expressed agreement whereas only 3.57 percent disagreed or strongly disagree, and 15.34 of the students take no extreme sides.

In response to question 16, which states that "online courses have support for evaluation of content, platform, service and course management", students also tended to agree with the statement. The result of table 5 shows that 80.46 percent of the sample expressed agreement, whereas only 3.36 percent expressed disagreement and 16.18 percent were uncertain. So it demonstrates that most students are well aware that the online courses have enough support for the evaluation of teaching and learning.

\subsection{Course Advance Operation and Effect}

This part includes four statements: the course platform has perfect functions and runs well; Advance courses studying has good teaching effects on the present course; Learners have a good course learning experience; The course has been positively evaluated by relevant institutions or organizations, and enjoys high social recognition. The result is shown in Table 6.

Table 6. Course advance operation and effect

\begin{tabular}{|c|c|c|c|c|c|c|c|c|c|c|}
\hline \multirow{2}{*}{$\begin{array}{l}\text { Statement } \\
\text { No. }\end{array}$} & \multicolumn{2}{|c|}{ Strongly agree } & \multicolumn{2}{|c|}{ agree } & \multicolumn{2}{|l|}{ Not sure } & \multicolumn{2}{|l|}{ Disagree } & \multicolumn{2}{|c|}{ Strongly disagree } \\
\hline & Frequency & Percent & Frequency & Percent & Frequency & Percent & Frequency & Percent & Frequency & Percent \\
\hline 17 & 238 & 50 & 142 & 29.83 & 75 & 15.76 & 13 & 2.73 & 8 & 1.68 \\
\hline 18 & 227 & 47.69 & 152 & 31.93 & 77 & 16.18 & 11 & 2.31 & 9 & 1.89 \\
\hline 19 & 228 & 47.9 & 151 & 31.72 & 73 & 15.34 & 15 & 3.15 & 9 & 1.89 \\
\hline 20 & 225 & 47.27 & 159 & 33.4 & 71 & 14.92 & 12 & 2.52 & 9 & 1.89 \\
\hline
\end{tabular}


Table 6 shows the result of the last four statements. For the statement 17 that the online course platform has perfect functions and runs well, 79.83percent of the students agree or strongly agree with it, and only 4.41percent disagree or strongly disagree with it. 15.76 percent are not certain.

In response to the statement 18 , which says that "early study of online courses has obtained a good teaching effect", while 79.62 percent 'agree' or 'strongly agree'; 4.2 percent 'disagree' and 'strongly disagree' and 16.18 percent of the students were not certain, as is shown in table 6 .

Statement 19 says that online course learners have a great course learning experience. 79.62 percent of the students 'agree' or 'strongly agree'; 4.04 percent 'disagree' and 'strongly disagree' and 15.34 percent of the students were not certain.

For the last statement that online courses have been positively evaluated by relevant institutions or organizations, with high social recognition, Responses show that 80.67 percent 'agreed' or 'strongly agreed' compared to only 4.417 percent who 'disagreed' or 'strongly disagreed' and 14.92 percent who were unsure.

\section{Factor Analysis of Teaching Quality Problems in Online Courses}

There are many factors affecting the quality of online teaching, including lack of self-discipline and adaptability in network learning, the Internet condition not to meet the demand of teaching, teachers' inflexible teaching methods in teaching, teachers' unskilled use of network teaching tools, lack of interactive teaching, less teaching resources to meet the demand of learning, students' unskilled use of network teaching tools, teachers' unconsciousness of how to carry out the teaching and learning under the network environment of understanding, etc. Based on the investigation and analysis of this research, the factors affecting the quality of online teaching can be classified as network environment factors, students' factors and teachers' factors.

\subsection{Network Environment Factors}

Internet access conditions in some areas are difficult to meet the teaching needs. During public health emergencies (e.g. Covid 2019 pandemic), all the students study at home and the Internet environment is the basic physical environment for students to participate in online teaching. Teaching live broadcast, teaching recording, downloading teaching resources, participating in online discussions, completing tests and assignments are all based on the Internet environment. The survey found that in some remote and rural areas, there is no Wi-Fi signal, no wireless router installed, and the mobile phone traffic is insufficient, leading to the online teaching unconnected to the Internet, the stuck network, unconnected to the earphone, bad sound and other conditions, affecting the effect of online teaching.

\subsection{Student Factors}

Students' self-discipline and adaptability in online learning is one of the factors that affect the quality of online teaching. Online learning based on the Internet makes face-to-face classroom learning at the same time and space into home learning where teachers and students are separated from each other. Without the direct guidance of teachers and the encouragement of face-to-face communication between students and partners, students can "show up" on time, but the effect of "concentrated attention" to participate in learning is not satisfactory. The mean value of students' adaptability to online teaching methods and "concentration" did not reach 4 , and the mean value of dimensions did not reach 4 either, indicating that the online learning adaptability of students still needs to be improved.

\subsection{Teacher Factors}

These factors include unskilled use of network teaching tools and the continuation of traditional classroom teaching thinking. As designers and organizers of online teaching, teachers' information technology literacy, online teaching philosophy and online teaching organization all affect the effect of online teaching. As can be seen from the above analysis, teachers' unskillfully using network teaching tools is also one of the factors affecting the effect of online teaching. In addition, some teachers' online teaching methods are inflexible and teaching interactions are insufficient. Teaching resources are difficult to meet the learning needs and other problems, which also highlight that the teachers' online teaching philosophy and teaching organization belong to the traditional classroom teaching thinking. They ignore the characteristics of the Internet, and have no thinking and practice for the teaching reform in the Internet environment. As a result, teaching objectives, teaching content and teaching activities in online teaching are difficult to adapt to online teaching, and online learning support services also need to be strengthened.

\section{Quality Optimization Strategies in Online Course Teaching}

Based on the background of "Internet plus Education", and integrating the online learning and classroom 
teaching, this study proposes the following strategies for optimizing the quality of online teaching in colleges and universities.

The construction of Internet basic environment is the basis for optimizing online teaching and promoting "Internet plus Education". At present, it is still needed to improve the universality and connectivity of network infrastructure, and improve the network speed, especially to increase network coverage in rural areas, enhance the connectivity of the network data and the open sharing of data resources, form the Unicom and Shared data platform, further to construct the network foundation environment adapting to education development level, break through the bottleneck of the Internet basic environment for the development of "Internet plus Education", and enhance the education support service for "Internet plus" through network connectivity.

We should also improve the online teaching ability of university teachers and promote innovation in the integration of information technology and education. Teachers are the implementers of classroom teaching and reform. The online teaching ability of teachers is the core basis for optimizing the quality of online teaching and promoting the innovation of the integration of information technology and education, and it also affects students' participation in learning. To improve the online teaching ability of university teachers, on the one hand, it is necessary to improve the application ability of information technology, including skilled use of information technology in teaching, the ability to promote learning, evaluation, service, and technical literacy; it is necessary for teachers to possess information literacy for retrieving, editing and using information creatively; It is necessary for teachers to possess data literacy for collecting data, mining data, and transferring data in teaching, learning and evaluating. On the other hand, teachers should focus on "learning" and have the teaching concept matching with online teaching. The Internet created a Shared, distributed, decentralized, nonlinear participatory culture, breaking the basic structure of unity and centricity in classroom teaching. Teachers should have the initiative to change the traditional teaching mode and the willingness to adapt to the online teaching and innovation, at the same time, meeting the students' personalized learning is also the core in classroom teaching reform. The research result also indicates the differentiated learning needs of students, which requires teachers to take the initiative to carry out teaching reform.

We should take "learning" as the center to design teaching and reconstruct the teaching process. Internet-based information technology is to promote the teaching reform, for example, MOOC is the open service model for innovation quality education. Big data makes it possible to accurately forecast, push and feedback. Teachers should design teaching with "learning" as the center and reconstruct the teaching process. First of all, give full play to students' subjectivity and empower students. In an open learning environment, students turn into "learners". Teachers should create a democratic and decentralized environment, give full play to students' subjectivity, empower students, and encourage students to make active choices and participate actively. Secondly, attach importance to the relationship between teaching elements and reconstruct the teaching process. Objectives, contents, teaching organization, teaching activities, evaluation and so on are interrelated with each other, and act together in the teaching process. The objectives are the unity of teaching and learning goals and they are negotiate with each other in the teaching process; Content is the unity of systematic teaching resources and personalized learning resources, which are generated and iterated in teaching. The teaching organization should not only give unified teaching, but also have independent learning, cooperative learning, personalized counseling, etc., and combine standardization with individuation. In addition to teaching, teaching activities should include various forms of activities, such as discussion, question answering, problem solving and group exploration, so as to stimulate students to share in participation. Evaluation not only points to the teaching process but also to the result feedback to improve teaching and learning. In short, teachers should integrate the time and space and activities in and out of class, online and offline, design teaching with "learning" as the center, and reconstruct the teaching process.

We should give full play to the key role of teachers' personalized learning support service and guide students to take the initiative in learning. Learning support service is the core element of guaranteeing distance learning outcomes. Online teaching transforms face-to-face teaching into "screen to screen teaching". Faced with differentiated learning demands, teachers should play a key role in personalized learning support services: From a "teacher" to a "designer of learning behavior", and to a "guide scholar", it is committed to providing personalized learning support for each student, and guiding students to take the initiative in learning with targeted continuous support services. Teachers can provide teaching support, management support, learning skill support, technical support, peer support, emotional support, off-campus support, etc. On the one hand, teachers promote independent learning with personalized learning support services, providing personalized cognitive guidance, learning scaffolds, ability development guidance, resource tools, learning incentives, reflective support, etc., to continuously stimulate students' learning motivation and promote independent construction. On the other 
hand, teachers promote cooperative learning with personalized learning support services. Learning is not only a kind of individual activities, but also a social activity. In cyberspace, teachers, students, contents and so on, are all knowledge network nodes. Social interaction between teachers and students can promote the creation of knowledge. Teachers should stimulate students to participate in topic discussion, problem solving, cooperation, exploration and other activities, and promote collaboration and dialogue among students by providing them the advice and guidance.

We should give full play to the platform and data support to enhance the evidence-based multiple evaluation and accurate feedback, give full play to the advantages of Internet platform and data recording, and enhance accurate feedback based on online "evidence". Using the platform, teachers can organize a variety of evaluation methods, such as students' self-evaluation, peer evaluation, teacher evaluation and automatic feedback of the platform, to guide students to participate in the learning process in different ways. At the same time, teachers can use online teaching platform of the boot and diagnostic data records. Online data records the student individuals to participate in the study of "trace", including the video watch, downloading, online speech, views to share resources, job submission, etc., focusing on the multiple perspectives before class, in class and after class, and even mass of individual data together forms the sources of course data. It reflects the learning process and growth process of students. Teachers can carry out multi-dimensional excavation and analysis. On the one hand, by collecting and mining data, the teacher can analyze student individual or group of students learning progress, potential problems to give an accurate feedback, such as providing supplementary learning resources, guiding the problem solving, etc. These can promote students' personal reflection, dig deep learning needs and promote their improvement of teaching. On the other hand, the results of data analysis will form the growth portraits of individual and group students, which will serve as the basis for the phased development of students, provide personalized feedback and prediction for students, and help students plan their next learning plan. In short, big data enables teaching thinking to change from asking "why" to exploring "what", to change teachers' and students' cognition of certainty of knowledge and their belief in the existence of knowledge, and promote students' growth in precise guidance.

\section{Conclusion}

Information technology must have a substantial connection with the core links of university education in order to maintain its vitality. Online teaching experience accelerates the process of higher education informatization and provides useful experience for deepening the reform of classroom teaching in colleges and universities.

This study examines the current situation and problems of online teaching quality in colleges and universities in central China, and puts forward optimization strategies under the background of "Internet plus Education", in order to promote the deep integration and innovation of information technology and classroom teaching.

\section{References}

Bernard, R. M., Abrami, P. C., Borokhovski, E., Wade, C. A., Tamim, R. M., Surkes, M. A., \& Bethel, E. C. (2009). A Meta-Analysis of Three Types of Interaction Treatments in Distance Education. Review of Educational Research, 79(3), 1243-1289. https://doi.org/10.3102/0034654309333844

Darling-Hammond, L., \& Bransford, J. (Eds.). (2007). Preparing teachers for a changing world: What teachers should learn and be able to do. Hoboken: John Wiley \& Sons.

De Wever, B., Schellens, T., Valcke, M., \& Van Keer, H. (2006). Content analysis schemes to analyze transcripts of online asynchronous discussion groups: A review. Computers \& Education, 46(1), 6-28. https://doi.org/10.1016/j.compedu.2005.04.005

Garrison, D. R. (2011). E-learning in the 21st century: A framework for research and practice. New York, NY: Taylor \& Francis.

Ginns \& Ellis. (2007). Quality in blended learning: Exploring the relationships between online and face-to-face teaching and learning. The Internet and High Education, 10(1), 53-64. https://doi.org/10.1016/j.compedu.2005.04.005

Graham, C., Cagiltay, K., Lim, B., Craner, J., \& Duffy, T. M. (2001). Seven principles of effective teaching: A practical lens for evaluating online courses. The Technology Source, 30(5), 50.

Haythornthwaite, C., \& Andrews, R. (2011). E-learning theory and practice. Sage Publications. https://doi.org/10.4135/9781446288566

Herrington, A., Herrington, J., Oliver, R., Stoney, S., \& Willis, J. (2001). Quality guidelines for online courses: The development of an instrument to audit online units. In M. K. G. Kennedy, C. McNaught, \& T. Petrovic 
(Eds.), Proceedings of 18th Conference of the Australasian Society for Computers in Learning in Tertiary Education (pp. 263-270). Melbourne, VIC.

Kidney, G., Cummings, L., \& Boehm, A. (2014). Toward a quality assurance approach to e-learning courses. International Journal on E-Learning, 6(1), 17-30.

Kyriakides, L., Christoforou, C., \& Charalambous, C.Y. (2013). What matters for student learning outcomes: A meta-analysis of studies exploring factors of effective teaching. Teaching and Teacher Education, 36, 143-152. https://doi.org/10.1016/j.tate.2013.07.010

Margaryan, A., Bianco, M., \& Littlejohn, A. (2015). Instructional quality of Massive Open Online Courses (MOOCs). Computers \& Education, 80(0), 77-83. https://doi.org/10.1016/j.compedu.2014.08.005

Tallent-Runnels, M. K., Thomas, J. A., Lan, W. Y., Cooper, S., Ahern, T. C., Shaw, S. M., \& Liu, X. (2006). Teaching courses online: A review of the research. Review of Educational Research, 76(1), 93-135. https://doi.org/10.3102/00346543076001093

Tamim, R. M., Bernard, R. M., Borokhovski, E., Abrami, P. C., \& Schmid, R. F. (2011). What forty years of research says about the impact of technology on learning a second-order meta-analysis and validation study. Review of Educational Research, 81(1), 4-28. https://doi.org/10.3102/0034654310393361

\section{Copyrights}

Copyright for this article is retained by the author(s), with first publication rights granted to the journal.

This is an open-access article distributed under the terms and conditions of the Creative Commons Attribution license (http://creativecommons.org/licenses/by/4.0/). 